\title{
Revealing the influence of hyporheic water exchange on the composition and abundance of bottom-dwelling macroinvertebrates in a temperate lowland river
}

\author{
Mateusz Grygoruk ${ }^{1, *}\left(0\right.$, Ewelina Szałkiewicz ${ }^{2}$, Maria Grodzka-Łukaszewska ${ }^{3}$, \\ Dorota Mirosław-Świątek ${ }^{1}$, Paweł Oglęcki ${ }^{1}$, Dorota Pusłowska-Tyszewska ${ }^{3}$ (D) Grzegorz Sinicyn $^{3}$ (1) \\ and Tomasz Okruszko ${ }^{1}$ \\ ${ }^{1}$ Institute of Environmental Engineering, Warsaw University of Life Sciences-SGGW, ul. Nowoursynowska 166, 02-787 Warsaw, Poland \\ ${ }^{2}$ Department of Hydraulic and Sanitary Engineering, Poznań University of Life Sciences, ul. Piątkowska 94A, 60-649 Poznań, Poland \\ ${ }^{3}$ Faculty of Building Services, Hydro and Environmental Engineering, Warsaw University of Technology, ul. Nowowiejska 20, 00-653 \\ Warsaw, Poland
}

Received: 28 February 2021 / Accepted: 27 October 2021

\begin{abstract}
We studied distributions and abundances of macroinvertebrates in relation to hyporheic water exchange (HWE) patterns of the upper Biebrza - a small, lowland, low dynamic European river located in Northeast Poland. On a 6-km stretch of the river; we determined the variability of water exchange in the hyporheic zone by using direct field measurements of the pressure gradient to determine groundwatersurface water interactions. We identified locations with upwelling and downwelling fluxes of HWE as well as ambiguous hydraulic contact between groundwater and surface water along the river. In these locations, we sampled bottom-dwelling macroinvertebrates. In total, 627 individuals of benthic macroinvertebrates of 34 taxa were identified. We revealed that bottom-dwelling macroinvertebrate fauna is more abundant and diverse in river stretches where water from the river infiltrates the hyporheic zone. Results also show higher taxonomic richness and abundances of benthic macroinvertebrates in stretches with diagnosed infiltrating conditions (downwelling flux in a hyporheic zone) compared to in stretches where the river drained groundwater (upwelling flux in a hyporheic zone), but the recorded differences were not statistically significant.
\end{abstract}

Keywords: Macroinvertebrates / hyporheic zone / flow / lowland / Biebrza

Résumé - Nous avons étudié la distribution et l'abondance des macroinvertébrés en relation avec les modèles d'échange d'eau hyporhéique (HWE) du cours supérieur de la Biebrza, une petite rivière européenne de plaine, peu dynamique, située dans le nord-est de la Pologne. Sur un tronçon de $6 \mathrm{~km}$ de la rivière, nous avons déterminé la variabilité des échanges d'eau dans la zone hyporhéique en utilisant des mesures directes sur le terrain du gradient de pression pour déterminer les interactions entre les eaux souterraines et les eaux de surface. Nous avons identifié les endroits présentant des flux ascendants et descendants d'HWE ainsi qu'un contact hydraulique ambigu entre les eaux souterraines et les eaux de surface le long de la rivière. Dans ces endroits, nous avons échantillonné des macroinvertébrés vivant sur le fond. Au total, 627 individus de macroinvertébrés benthiques de 34 taxons ont été identifiés. Nous avons révélé que la faune de macroinvertébrés vivant sur le fond est plus abondante et diversifiée dans les tronçons de rivière où l'eau de la rivière s'infiltre dans la zone hyporhéique. Les résultats montrent également une plus grande richesse taxonomique et une plus grande abondance des macroinvertébrés benthiques dans les tronçons où les conditions d'infiltration ont été diagnostiquées (flux descendant dans une zone hyporhéique) par rapport aux tronçons où la rivière a drainé les eaux souterraines (flux ascendant dans une zone hyporhéique), mais les différences enregistrées n'étaient pas statistiquement significatives.

Mots clés : Macroinvertébrés / zone hyporhéique / débit / plaines / Biebrza

\footnotetext{
*Corresponding author: mateusz_grygoruk@sggw.edu.pl
} 


\section{Introduction}

Groundwater-surface water interactions in rivers influence a range of ecological processes, and are an interdisciplinary research challenge (Lewandowski et al., 2020). In low dynamic lowland rivers (water table slope \pm 0.002 ; average annual cross-section flow velocities are lower than $0.1 \mathrm{~m} / \mathrm{s}$ ), habitat conditions for biota are suspected to be driven by not only water depths, sediment types and flow velocities, but also variables in space (i.e., the direction of groundwater-surface water interactions) (Mathers et al., 2016). Changing the draining/infiltrating role of the river to adjacent groundwaters underpins the variability of water temperature in the un-mixed zone of bottom sediments at the meso- and micro-habitat scale. This provides specific conditions for bottom-dwelling macroinvertebrates (BMI) and rooting macrophytes (Bradley et al., 2014 ; Conant Jr. et al., 2019; Jekatierynczuk-Rudczyk, 2007; Magliozzi et al., 2019; Packman and Bencala, 2003; Pepin and Hauer, 2002). Water filtration from the river to the aquifer allows higher oxygenation of the hyporheic zone's superficial layers as well as relative warming-up of the interstitial waters (Anibas et al., 2011). Draining groundwater by the river contradictorily results in zonal lowering river water temperature and remains responsible for reducing the oxygen content in interstitial waters (Kalbus et al., 2006).

The balance of river-groundwater interactions is dependent on hydraulic heads in the open channel-flowing water and in the adjacent phreatic/vadose aquifer (Fleckenstein et al., 2010). Hydraulic relationships between groundwater and surface water of rivers results from the river valley's different hydrogeological setup and actual hydrological conditions. Groundwater-surface water interactions in the hyporheic zone present various dynamics. They can remain nearly constant in space (as driven by both the riverbed's morphology and sediment types, and the similar direction of a gradient between the river water levels and adjacent groundwater pressure heads). However, at the same time, the groundwater-surface water interactions that influence the hyporheic zone's biogeochemical conditions also can be highly variable in the scale of a river element (stretch/bend/pool/riffle), independently from the rivers' size and their hydraulic conditions (Anibas et al., 2012; Pacman and Bencala, 2003). This influences interstitial water temperature and the aquatic ecosystem's related ecological features. Recent advances in assessing habitat conditions of rivers identified groundwater-surface water interaction-driven changes in water temperatures as a field then need to be explored towards improving the management of habitat (Campbell et al., 2020). The first steps towards evaluating the influence of hyporheic water exchange (HWE) on BMI in different scales provided interesting results. Ling et al. (2020) observed that hyporheic upwelling flows, representing the river's draining conditions cause resuspension of finer sediments and increase the proportion of swimmers (in their case, Baetidae) in total abundance of BMI. They also observed that downwelling flows (representing conditions of river infiltration to the aquifer through the hyporheic zone) produced richer compositions and abundances of BMI than the upwelling ones. Some studies also showed that the influence of other environmental factors affecting hydromorphology were likely to induce HWE changes, which likely results in changing environmental conditions within the BMI's habitat niche (Magliozzi et al., 2019). To understand the variability of groundwater-surface water interactions in the Upper Biebrza (Anibas et al., 2012; Diaz et al., 2020) and to fill knowledge gaps on the near-natural status of this river, we conducted interdisciplinary research to identify HWE, selected hydraulic parameters of the river and abundances and taxonomic compositions of BMI, and make an attempt to reveal the interconnections between these processes. We hypothesized that (1) the distribution and taxonomic diversity of bottom-dwelling macroinvertebrates present different patterns that correspond to variable in-space conditions of HWE, and (2) the directions of HWE in a low dynamic, temperate, perennial lowland river influence the spatial patterns and the composition of bottom-dwelling macroinvertebrates more than the other environmental variables, such as the ones resulting from the river's hydromorphology and hydraulics. In our study, we attempted to (i) identify dominant patterns of groundwater-surface water interactions in a section of the natural lowland Biebrza river that has not been exposed to any management measures since the 1990s, (ii) sample BMI and describe their families, genera, and other taxonomical orders and the abundances of BMI, and (iii) compare whether any of the indices describing abundances and diversities of macroinvertebrates can be attributed to changing groundwater-surface water interactions.

\section{Materials and methods}

\subsection{Study area}

We studied the distribution of macroinvertebrates, groundwater-surface water interactions and a range of hydraulic parameters of a $6-\mathrm{km}$ stretch of the perennial low dynamic, temperate lowland Biebrza river located in Northeast Poland (Fig. 1). The studied river segment located between the bridge in the village Koniuszki $\left(53.702183^{\circ} \mathrm{N}, 23.464670^{\circ} \mathrm{E}\right)$ and the confluence of the Sidra river to Biebrza $\left(53.701697^{\circ} \mathrm{N}\right.$, $23.409691^{\circ} \mathrm{E}$ ) was small (max width $8 \mathrm{~m}$; max depth $2 \mathrm{~m}$ ) with low flow dynamics (flow velocities varying from $0.0-0.3 \mathrm{~m} / \mathrm{s}$ ). The average annual precipitation in Różanystok rain gauge is $574 \mathrm{~mm}$. The average discharge of Biebrza in Sztabin is equal to $4.86 \mathrm{~m}^{3} / \mathrm{s}$ and varies from $0.32 \mathrm{~m}^{3} / \mathrm{s}$ (lowest discharge recorded in this water gauge) up to $96 \mathrm{~m}^{3} / \mathrm{s}$ (highest discharge recorded in this water gauge; Chormański et al., 2011). The river's slope is equal to 0.0015 . The research area is located in the temperate climate zone with strong continental influence.

The average recorded annual air temperatures is $7.4^{\circ} \mathrm{C}$ but records strong inter-seasonal variability, minimum $-25^{\circ} \mathrm{C}$ in winter (January-February) and a maximum of $35^{\circ} \mathrm{C}$ in summer (July-August) (Grygoruk and Rannow, 2017). The average terrain elevations of the study site is approximately $125 \mathrm{~m}$ a.s.1. and most of this glacial-formed land depression is covered with a peat layer with max. $8 \mathrm{~m}$ thickness, which developed in a postglacial depression (Zurek, 2005), providing perfect conditions for the development of minerotrophic fens directly adjacent to the river. The riverbed is seldom incised to the sandy bedrock and accumulation of very fine-grained, preliminarily organic sediments has formed approximately $1.5 \mathrm{~m}$-thick, which is a homogenous layer along the whole river stretch. In summer, the river is densely vegetated by Nuphar lutea, Sagittaria sagittifolia, Phragmites australis and Potamogeton sp., providing suitable 


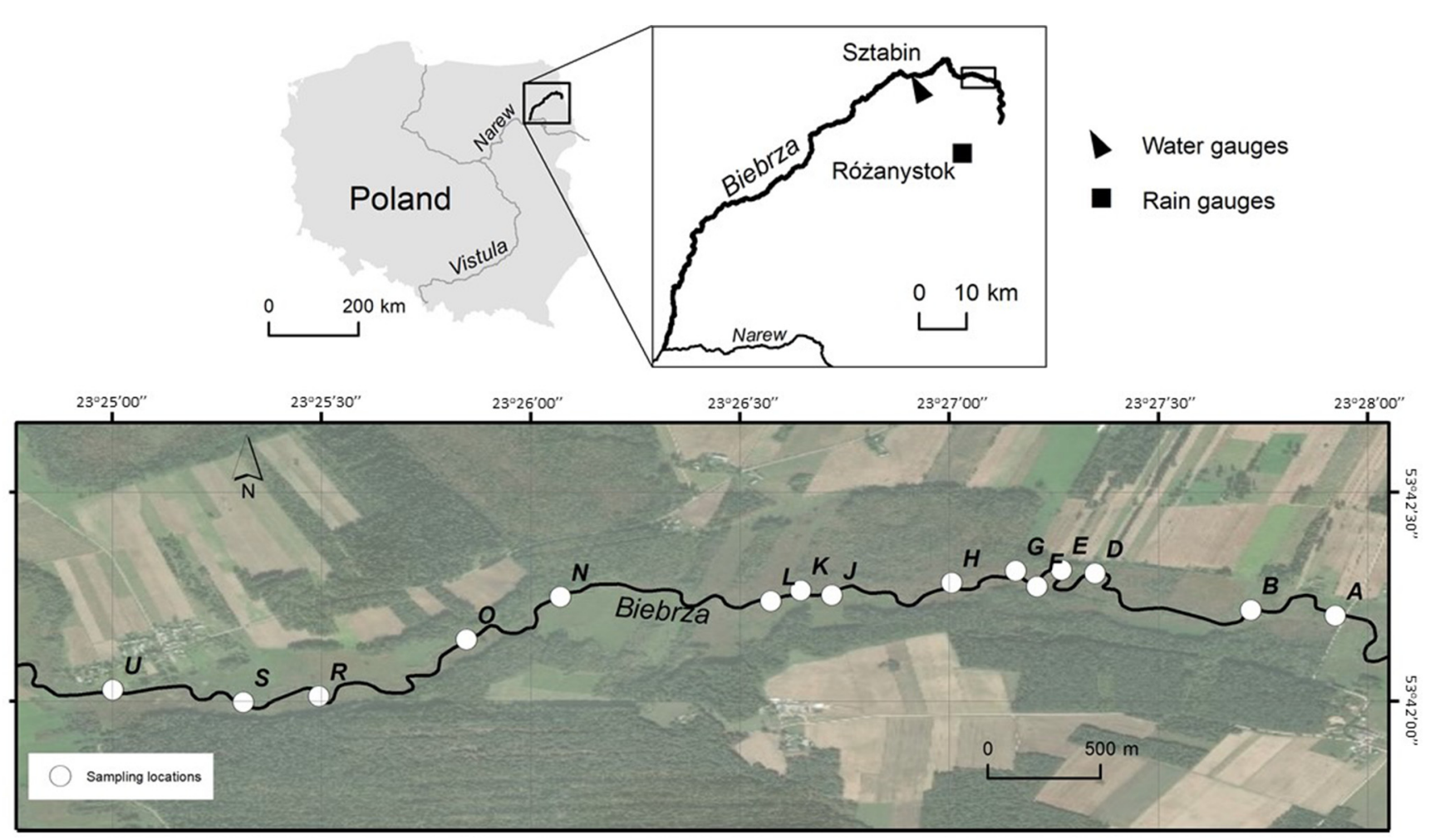

Fig. 1. Research area - a stretch of river Biebrza in the Upper Basin of the Biebrza Valley (NE Poland).

refuge for a range of fish and macroinvertebrates. In this season, water in the upper Biebrza is turbid (visibility $\pm 0.5 \mathrm{~m}$ ) whilst in cold seasons (November-April) water is more transparent (visibility $\pm 3.0 \mathrm{~m})$.

\subsection{Hyporheic water exchange research}

Throughout the 6-km stretch of the river, we determined variability of HWE by using direct field measurements. HWE was measured with a hybrid-design Lee-Cherry minipiezometer (1978, after Sanders 1998) and a gradientometer (Marciniak and Chudziak, 2015). The device allowed measuring surface waters with different bottom characteristics (no restrictions related to the type and thickness of bottom sediments). Detailed description of the method applied in these measurements is provided by Grodzka-Łukaszewska et al. (2021). The character of water exchange between the river and the aquifer is determined immediately after the device's measuring conditions have stabilized (about $15 \mathrm{~min}$ ). Pressure heads measurement campaigns were conducted during three periods: 4-5 July 2018, 3 November 2018, and 25 June 2019. Using the developed device, we could detect the river character (infiltration/drainage) in chosen locations of the Biebrza river, where macroinvertebrates were sampled for the purposes of this study (Fig. 1). Analysis of groundwater-surface water interactions at the river stretch examined in this study was described in detail in Diaz et al. (2020).

\subsection{Sampling of macroinvertebrates}

Macroinvertebrates were sampled in two field campaigns performed in September 2017 and June 2018 by using the
Ekman-Birge sampler, according to the BMPW-PL protocol (Klimaszyk and Trawiński, 2007), in 15 sites distributed along the research stretch of Biebrza (Fig. 1). In each of the 15 locations, three samples were collected along the cross-section of the river and the results of sampling were integrated to represent the abundance and composition of BMI in every particular research location. Collected individuals of BMI were identified to the lowers possible taxonomic level and released to the river immediately after sampling, according to the protocol Kołodziejczyk and Koperski (2000) provided for Polish water bodies. Individuals that could not have been identified in the field (approximately $30 \%$ of the individuals) were collected and identified in the laboratory. The list of sampled taxa was used to form a dataset to be analysed. Further, the list of taxa and abundances of particular taxa's individuals formed important documentary material towards managing aquatic ecosystems of the Biebrza National Park. During field research, river discharge was nearly equal to the average, multi-year value proving that sampling conditions were similar in both sampling campaigns.

\subsection{Statistical analyses}

First, we analyzed the basic statistical indicators of BMI, such as the numbers of taxa, numbers and Biological Monitoring Working Party score (BMWP) for each research location, integrated to represent infiltrating, draining and ambiguous conditions of HWE. In the second step, we performed analyses comparing taxonomic structures of organisms (Graeber et al., 2013; Vimos-Lojano et al., 2020). The analyses of similarities (ANOSIM) was applied sensu Clarke (1993). The test compares mean dissimilarities 


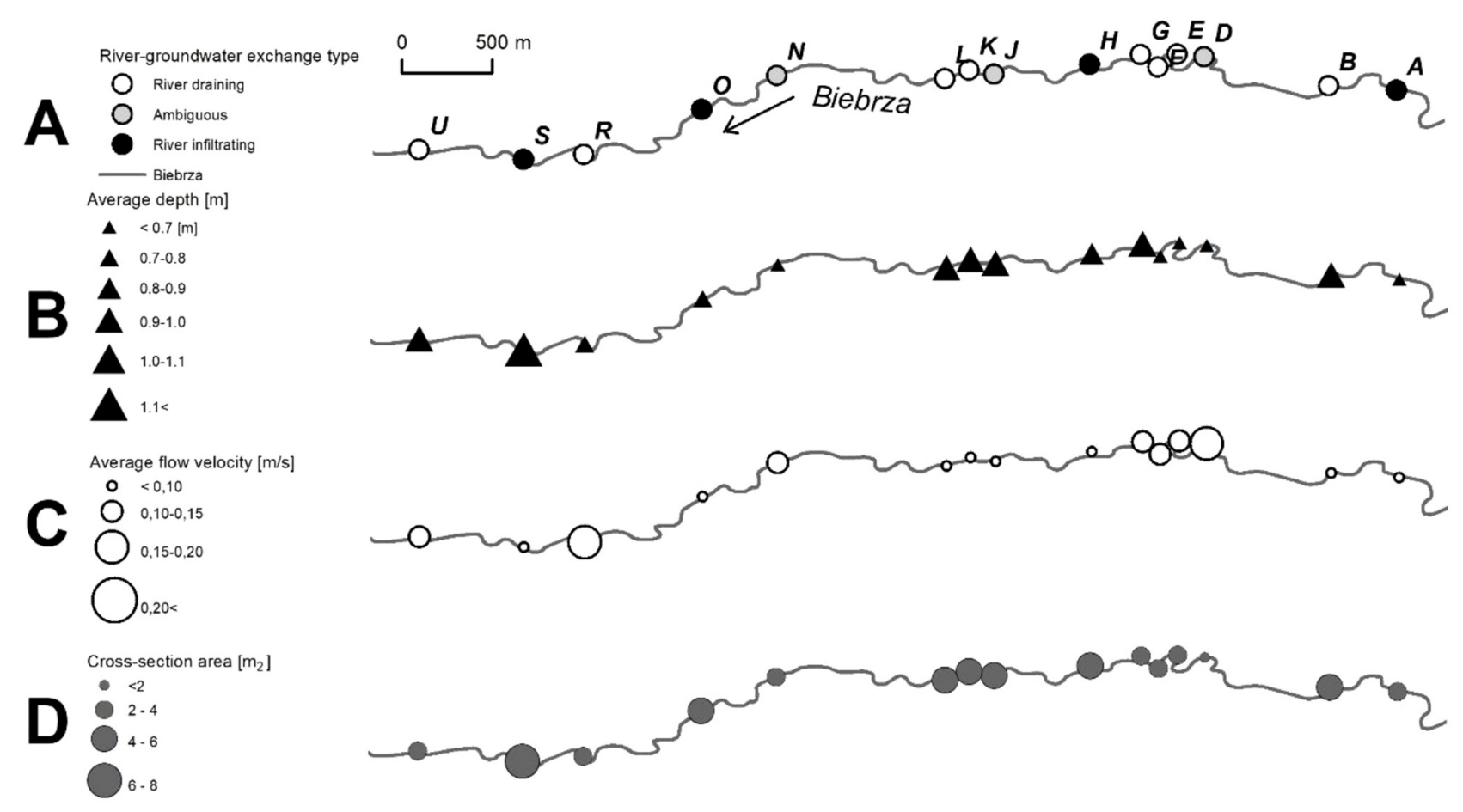

Fig. 2. Hydrological features of the river Biebrza: A - type of groundwater-surface water interaction; B - average depth in research sites; $\mathrm{C}$ - average cross-sectional flow velocities; D - areas of cross-sections through the river.

between groups with mean dissimilarities within groups. As a result, the $\mathrm{R}$ parameter is obtained, whose values closer to 1 indicate similarity between the groups, values closer to 0 suggest an even distribution of ranks within and between the groups, and values below 0 indicate greater similarities within the groups than between them (Clarke and Gorley, 2006). ANOSIM also provides information on the results' statistical significance (Clarke and Gorley, 2006). The matrix of dissimilarities was determined with the Bray-Curtis dissimilarity index and the number of permutations was 999. For each sample, the component indices of the Polish Multimetric Index of Ecological Status of Rivers MMI PL were also calculated: ASPT, Log10(sel EPTD+1), 1-GOLD\%, S, EPT and H (Bis and Mikulec, 2013, Lewin et al., 2014). The significance of differences between the results was checked using the $U$ Mann-Whitney test. The nMDS (non-metric Mulitidimensional Scaling) analysis was also performed as an iterative procedure for constructing an MDS chart by successively specifying the position of points until they met, as closely as possible, the sample dissimilarity relationships (Clarke and Warwick, 2001). The analysis consisted of the following steps: (1) determining the number of dimensions on the ordinance diagram (2-dimensional diagram), (2) preparing an initial table with the number of taxa in individual samples and the values of environmental parameters, (3) determining the location of points based on ranks determined from the dissimilarity matrix, and (4) checking the matching of point locations with the regression model using the so-called stress value (Clarke and Warwick, 2001). The Bray-Curtis dissimilarity index was used to determine the dissimilarity matrix, similarly to ANOSIM analyses. Maximum number of permutations was 999. The results of the nMDS analysis were supplemented with gradients of environmental parameters (measured for each sample, values of depth and flow velocity) and calculated indices of MMI PL index. The vector parameters were iteratively adjusted to the ordinance values (along the NMDS1 and NMDS2 axes; the number of permutations was 999). All analyses were performed in R. For ANOSIM and nMDS, an additional "vegan" package was used. The significance level for each test was $\alpha=0.05$.

\section{Results}

\subsection{Hyporheic water exchange and hydraulic parameters of the river}

Research on HWE along the stretch of the Upper Biebrza river presented variable conditions, but in general, directions of water exchange were similar in each of the field campaigns at particular points. Locations with strong upwelling fluxes (the river's draining role) were intersected with locations of downwelling fluxes (the river's infiltrating role; Fig. 2A).

In some places, gradients between groundwater pressure head in the hyporheic zone were equal to the water levels in the river, providing ambiguous water exchange conditions. Hydraulic parameters of the river channel also presented some variability, but all of them remained in a range typical for lowland European rivers. The river's average depths and average flow velocities in cross-sections presented intuitive, inversed correlations (the shallower the profile, the larger the velocity; Fig. 2B-C). Cross-sections' areas were correlated with average depths, provided that the largest wetted perimeter was occurring in the deepest profiles (Fig. 2D). We revealed that none of the analysed physical parameters of river channel remain correlated ( $T$-test; $p>0.05$ ) and distributions of average river depths, flow field and average flow velocities in 

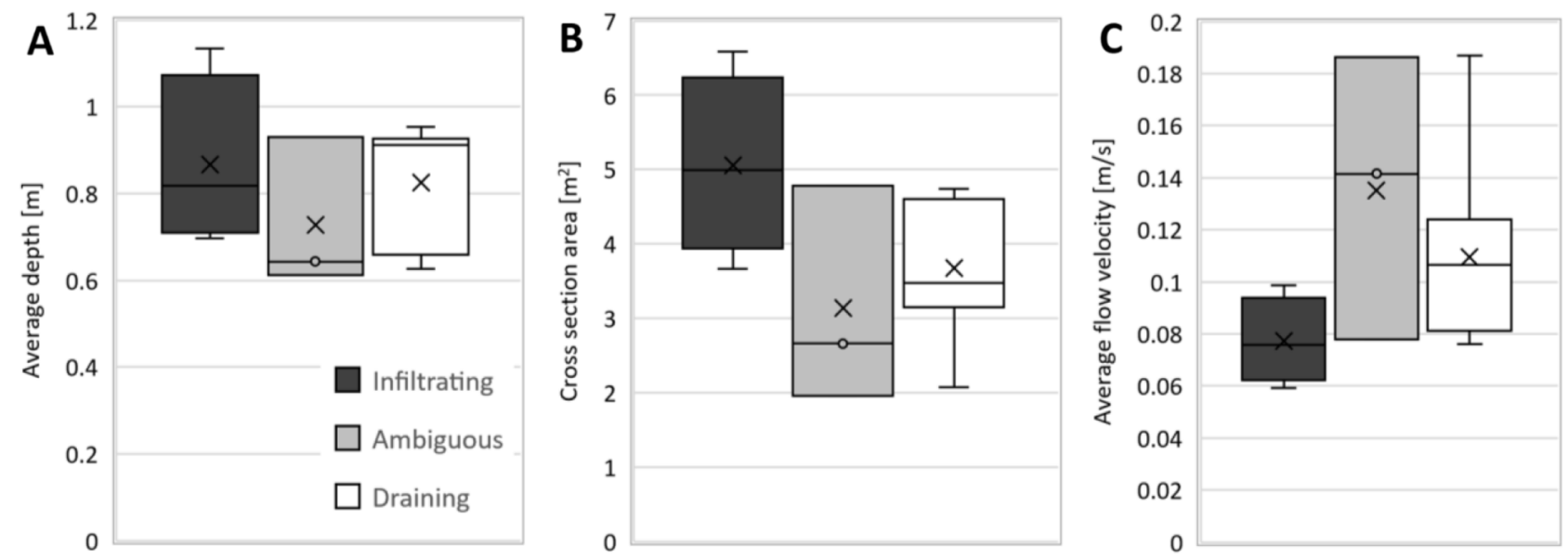

Fig. 3. Distributions of average river depths (A), cross-section areas (B) and average cross-sectional flow velocities (m/s) in locations of BMI sampling differentiated into infiltrating, draining and ambiguous stretches of river.
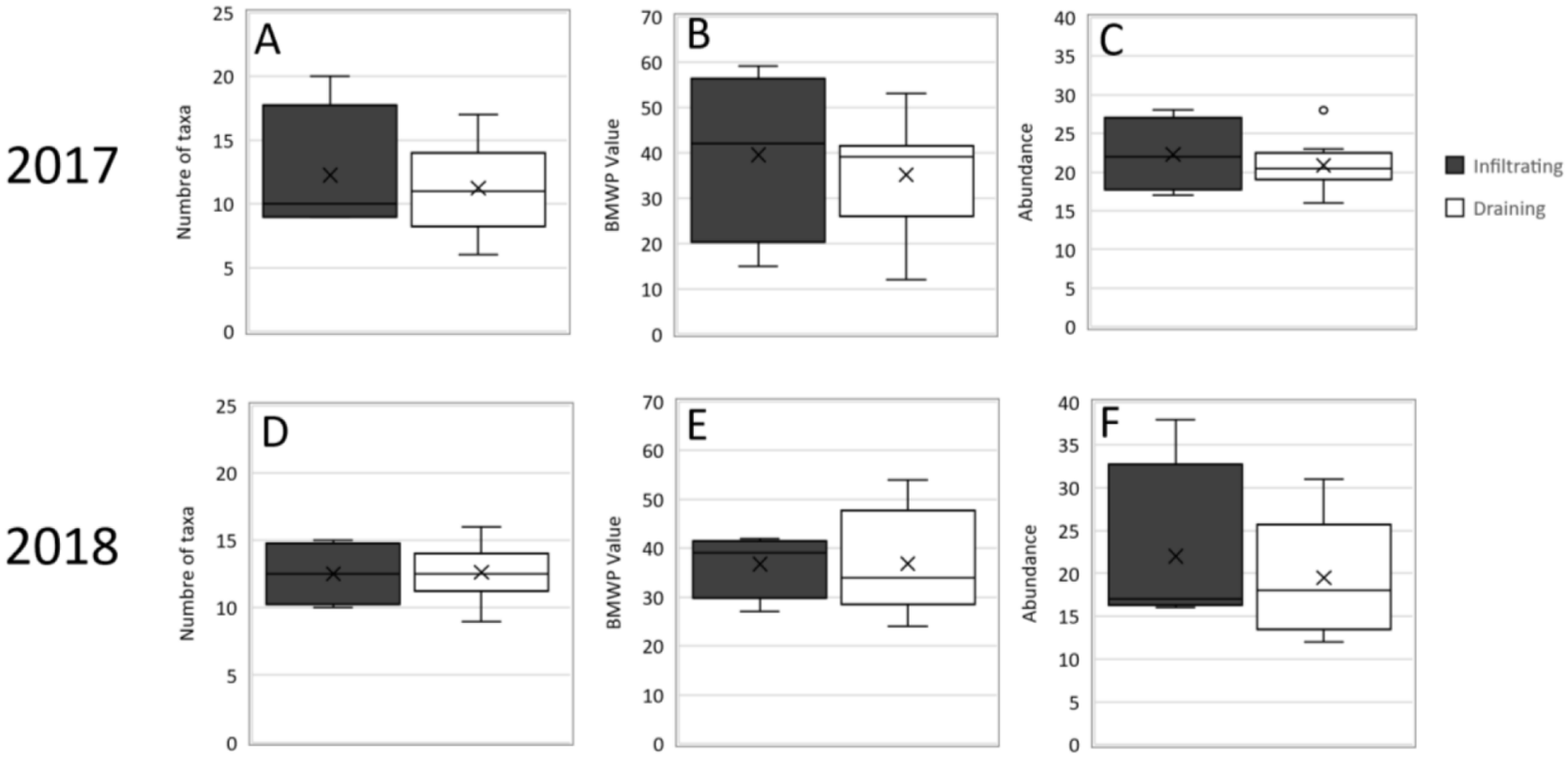

Fig. 4. Number of taxa (A, D), BMWP values (B, E) and total abundances (C, F) of BMI in sampling sites in 2017 (A-C) and 2018 (D-F) specification for infiltrating and draining conditions. $\mathrm{X}$ within the boxes stands for the average value. Solid line within the boxes represent average value. Box covers 25-75 percentiles of the parameter values distribution. Whiskers stand for 5-95 percentiles of the parameter values distribution.

the sampling locations did not present any patterns that could indicate bias in differentiation of HWE into infiltration, drainage or ambiguity of groundwater-surface water interaction (Fig. 3). However, we can conclude that infiltrating conditions (downwelling water flux in a hyporheic zone) were predominantly occurring in places of the highest average depths of river channel (Fig. 3A) and thus, flow velocities were the lowest (Fig. 3C) in the largest cross-section area (Fig. 3B). There were contradictive conditions: lower average depths, lower cross section's areas and higher average cross-sectional flow velocities occurred in locations with the river's draining influence (upwelling water flux in a hyporheic zone) on hyporheic waters. Results of the HWE partly confirmed the results Anibas et al. (2012) presented as to the distribution of upwelling and downwelling HWE, allowing to hypothesize that groundwater-surface water interactions present stability over time.

\subsection{Macroinvertebrates of the Upper Biebrza}

Raw data on collected macroinvertebrates along with coordinates of their collection site are presented in the supplementary material, Table S1. In total, 627 individuals of BMI of 34 taxa were identified (see supplementary material, Fig. S1A). The most abundant were Chironomidae, Nematoda 

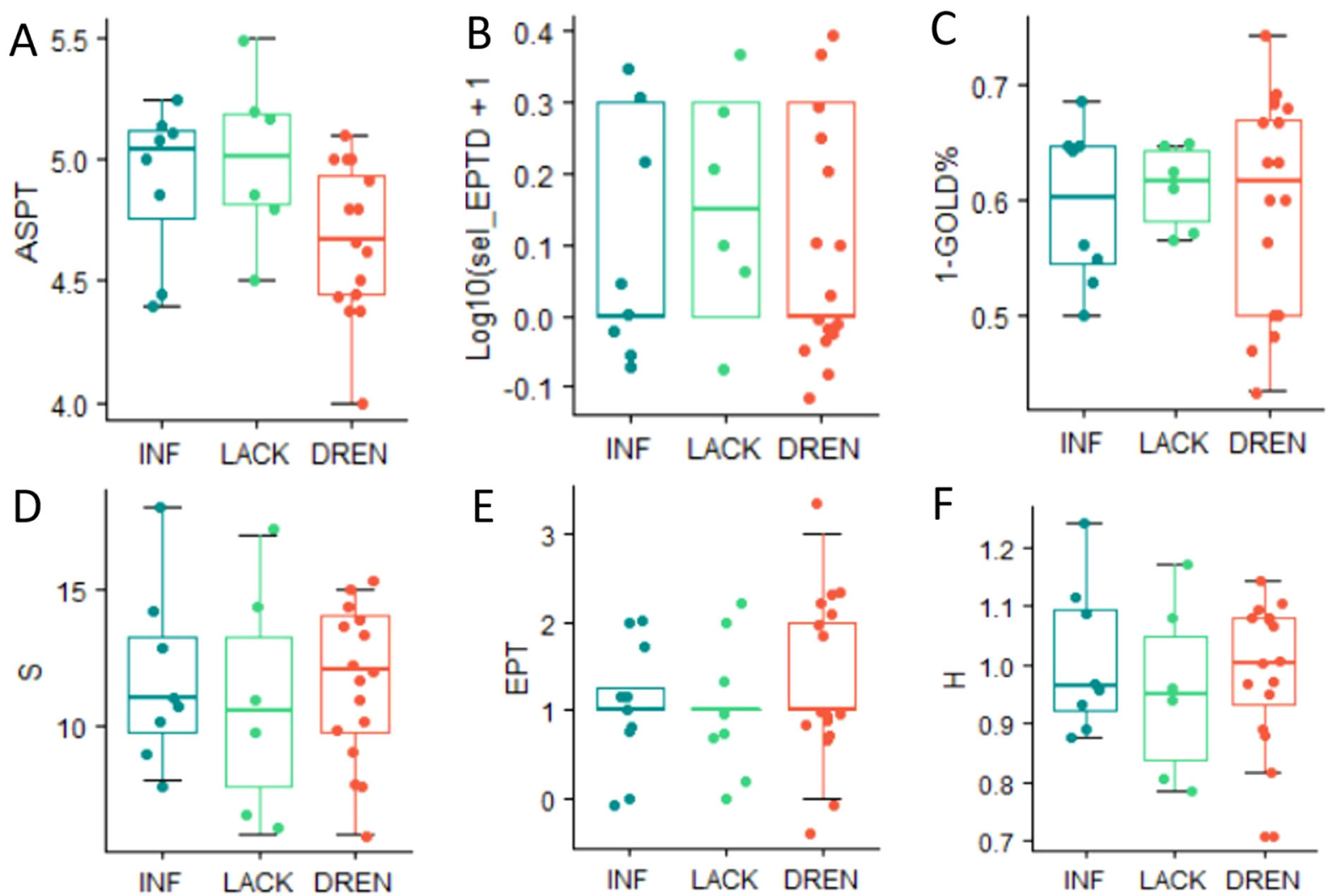

Fig. 5. A - average score per taxon (ASPT; consistent with the scoring scale of BMWP_PL after Klimaszyk and Trawiński, 2007); B - log10 of the sum of individuals from selected families: Heptageniidae, Ephemeridae, Leptophlebiidae, Brachycentridae, Goeridae, Polycentropodidae, Limnephilidae, Odontoceridae, Dolichopodidae, Stratiomyidae, Dixidae, Empididae, Athericidae, Nemouridae $+1, \mathrm{C}-1-\mathrm{GOLD} \%=1-$ (frequency, i.e. \% of the number of individuals from group of families Gastropoda + Oligochaeta + Diptera); D - the number of all families found in a given sampling location; E - number of organisms in orders: Ephemeroptera, Plecoptera and Trichoptera) found in a given sampling location; F - Shannon-Wiener diversity index. Solid line within the boxes represent average value. Box covers 25-75 percentiles of the parameter values distribution. Whiskers stand for 5-95 percentiles of the parameter values distribution.

and Daphnia (although Daphnia does not belong to BMI, we decided to report it as one of the taxa sampled), as it dominated compositions in both research campaigns and remained relatively uniformly distributed between the sites sampled (Fig. S1B). Gerris sp. Coenagrion sp., Simulium sp. and Hydropsyche sp., although not the most abundant in total number of individuals, along with Chironomidae, Nematoda and Daphnia, were found in the majority of sites sampled. Other taxa, such as Nepa cinerea, Oroconectes limosus, Glossiphonia complanata and Bosmina sp. (although Bosmina $s p$. does not belong to BMI, we decided to report it as one of the taxa sampled), were found only in one of the campaigns (June 2017). Among indicator taxa, we found Ephemera sp. and Caenis sp., which are usually present in the oligotrophic conditions. We also found relatively abundant Hydropsyche sp. that remain typical for solid bottom and fast current conditions (Kubosova et al., 2010), and are only seldomly found in the Upper Biebrza. Erpobdellidae and Chironomidae were abundantly present in some $50 \%$ and $100 \%$ of the sites, respectively, which indicate eutrophic conditions. The abundant presence of Gammaridae and Ephemeridae indicate high detritus content, which is typical for rivers developed in valleys with a thick cover of organic soils underlaid with the gyttia substratum.

\subsection{Macroinvertebrates vs. hyporheic water exchange}

We recorded slightly higher taxonomic richness and BMWP values of BMI in stretches with diagnosed infiltrating conditions (downwelling flux in a hyporheic zone) than in stretches where there was river-drained groundwater (upwelling flux in a hyporheic zone). Although HWE and BMI sampling were not done simultaneously, the former presented high stability over time, allowing to be considered constant (as to the direction of HWE) over time. However, none of differences were statistically significant ( $p=\{0.678,0.960\}$; (Fig. 4A-B; D-E). Similar patterns in these relations in the given indicators were observed in both years of research. We also found that the total abundances of BMI in stretches with diagnosed infiltrating river conditions (downwelling HWE flux) were slightly higher than in the upwelling HWE fluxes (Fig. 4C and F).

Analysis of the average score per taxon indicator (ASPT; Fig. 5A), which remains consistent with the scoring of BMWP, allows to conclude that taxa found in locations of downwelling flux of HWE remain higher scored than the ones persisting in zones with upwelling fluxes. Average values of BMWP for the analysed stretch of the Biebrza river ranged from 36 up to 40 (Fig. 4B and E), allowing to conclude that the river's 

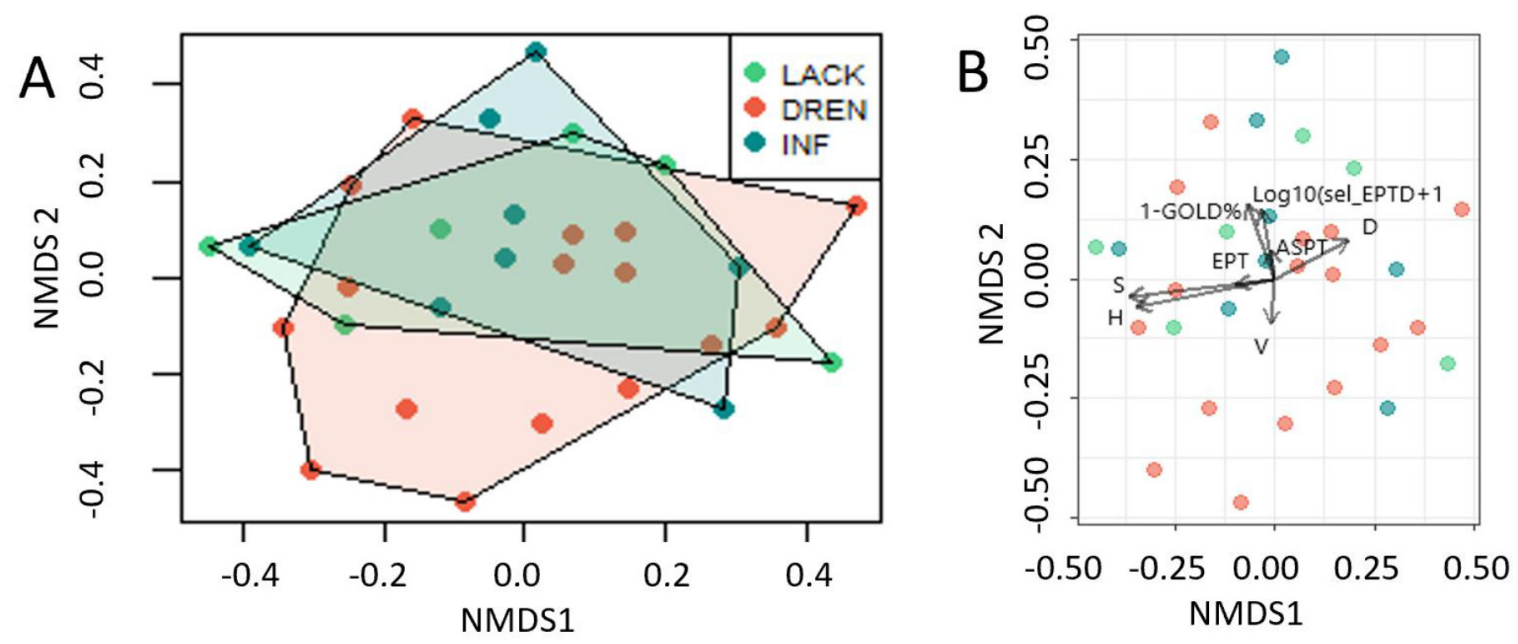

Fig. 6. Non-metric Multidimensional Scaling (NMDS) in ordinations - A - ranges of similarities for different HWE fluxes: INF - infiltration: downwelling flux, DREN - draining: upwelling flux, LACK - ambiguous HWE. B - NMDS matrix with vectors of environmental variables D - vector of average river depth; V - vector of average flow velocity.

ecological status is moderate to low (in the BMWP PL classification that Klimaszyk and Trawiński described (2007)).

ASPT scoring of BMI found in locations of ambiguous flux that lacked a dominant trend of water exchange (or, HWE remains multidimensional) was higher than the ASPT of both infiltrating and draining conditions, which allows to suspect that the direction of HWE in the case described cannot be considered a factor influencing the Biebrza River's ecological status. Summaric abundances of Gastropoda, Oligochaeta and Diptera (Fig. 6C) also does not allow us to conclude about the possible influence of directions of HWE on these taxa's distribution.

Average values of ASPT for the analysed stretch of the Biebrza river ranged from 4.70 up to 5.05 , thus allowing us to conclude that the river's ecological status is moderate. Analysing abundances of individuals from indicator families of Heptageniidae, Ephemeridae, Leptophlebiidae, Brachycentridae, Goeridae, Polycentropodidae, Limnephilidae, Odontoceridae, Dolichopodidae, Stratiomyidae, Dixidae, Empididae, Athericidae and Nemouridae (Fig. 5B), we found neither clear patterns nor any significant differences that would allow us to specify which of the analysed directions of HWE provided better habitat conditions for these taxa. Average values of $1-G O L D \%$ indicator remained similar between the sites with downwelling fluxes (river infiltration), upwelling fluxes (river draining groundwater) and ambiguous conditions (Fig. 5C). Variability of 1-GOLD\% was slightly larger in sites with diagnosed upwelling flux than in sites where HWE was downwelling. Similar relations were found in numbers of BMI families among the sampled sites (Fig. 5D). Values of EPT (Fig. 5E) remained much less variable among the sites of downwelling HWE and lower than among the sites of upwelling HWE. This may result from the fact that in draining conditions, when the river receives the inflowing cold groundwater, habitat conditions remain more constant, which Ephemeroptera, Plecoptera and Trichoptera are more likely to prefer (Principe and Marquez, 2019).

We also revealed that the values of Shannon-Wiener diversity index were slightly higher among the sites of downwelling HWE (from 0.88 up to 1.27 ) than among the sites with diagnosed upwelling HWE (from 0.82 up to 1.14; Fig. 5F). Analysis of Non-metric Multidimensional Scaling (NMDS) in ordinations revealed that samples originating from sites of different HWE conditions did not present significant dissimilarities and taxa that represent the same functional groups did not group, covering similar ranges of the NMDS matrix (Fig. 6). BMI revealed in sites of an upwelling HWE fluxes were likely to be linked to small river depths and higher flow velocities. BMI revealed in sites of a downwelling HWE flux tended to prefer larger river depths and lower flow velocities (Fig. 6b. However, again, the differences remained insignificant.

\section{Discussion and conclusions}

Results presented in this study allowed us to verify two hypotheses stated in our research protocol. First, we revealed that the distribution and taxonomic diversity of bottomdwelling macroinvertebrates presented different patterns in conditions of upwelling and downwelling fluxes of HWE. Second, we also revealed that HWE in the examined low dynamic, temperate, perennial lowland river cannot be considered a factor to explain distributions, spatial patterns and composition of bottom-dwelling macroinvertebrates better than the other environmental variables, such as river depths, flow velocities and cross-section's area, which confirmed to a certain extent the conclusions of Monk et al. (2006). Although statistical significance in different indicators of BMI abundances and compositions analysed in our study was not found, observed relationships remained similar to the ones Ling et al. (2020) provided: infiltrating conditions, where river waters penetrate hyporheic zone in a downwelling flux, prerequisited more suitable conditions for BMI persistence than the conditions of groundwater exfiltration (upwelling flux in a hyporheic zone). They also observed that hyporheic upwelling flows, representing the river's draining conditions, caused resuspension of finer sediments and increased the proportion of swimmers in total abundance of BMI. In our 
research, we did not consider the turbidity in the analysis because river flow velocities were very low (typically around $0.06-0.18 \mathrm{~m} / \mathrm{s}$ ) and high turbidity of the river water in summer seasons provides noises in sampling of suspended material that would make the research biased. A different pattern was observed in Campbell et al. (2020) study, where in a groundwater-fed stream compositions and abundances of macroinvertebrates were higher than in a surface-water stream. However, they investigated two different streams, thus it is likely that the repetition of their research within one river (or even one short river stretch) would provide different results.

The role of HWE in shaping compositions and abundances of BMI in small lowland rivers may change if the ongoing climate change (especially severe summer droughts occurring in temperate Europe in 2015-2020) will keep entailing perennial rivers turning intermittent, which would increase the role of groundwater discharge to sustain aquatic ecosystems in long, low-flow periods (such as Wood and Armitage (2004) and Armitage and Petts (1992) described). Results provided in our study, as a documentation of BMI structure in the Upper Biebrza, are the first comprehensive inventory of this site's benthic macroinvertebrates and remain an addition to documentary studies performed in the Biebrza Valley in the past (such as Obolewski et al., 2014). We suggest that future research in this field should address precise quantification of river habitat structure, macrophyte distribution and other hydrological indicators and - along with HWE - to be used to formulate the research setup to determine key environmental variables responsible for BMI structure and abundance in the Biebrza River. Considering the results of Bączyk et al. (2018) and Grygoruk et al. (2015), which claimed the BMI populations respond negative to river maintenance measures that aim at decreasing water levels and decreasing roughness of river channels. Moreover, awareness is needed that the dredging of rivers may also change directions of HWE fluxes from downwelling into upwelling (changing river-aquifer interaction). In the light of our study's results, we suggest that future research in this field should address the hypothesis that negative responses of BMI to river management can also result from this flux's switched directions that usually turn downwelling flux of river recharging the aquifer into homogenous draining conditions (upwelling flux), when river intensively drain adjacent groundwater. However, this fact should be studied in more detail, preferably in the before-after control-impact studies, where direct influences of river dredging and changing directions of HWE can be examined along with the sampling of BMI. Such studies would allow more detailed perception of river conservation, e.g., by specifying new indices for environmental flows formulation (Acreman and Dunbar, 2004).

\section{Author contributions}

MG developed the concept of this study, performed analyses and wrote the manuscript. MG- $€$ and GS conducted groundwater-surface water interaction measurements. PO performed field investigation and laboratory analysis of benthic macroinvertebrates. DM-S provided hydraulic parameters of the river channel. ES performed statistical analyses and discussed the results. DP-T and TO assisted in manuscript preparation, results description and discussion. All authors have read and agreed to the final version of the manuscript. We sincerely thank Michael Manton for proof-reading the manuscript.

\section{Supplementary material}

Table S1 Raw data from benthic macroinvertebrates sampling.

Figure S1 Abundances and distributions of BMI in the Upper Biebrza in 2017 and 2018.

The Supplementary Material is available at https://www. kmae-journal.org/10.1051/kmae/2021036/olm.

Acknowledgements. This research was funded by National Science Centre $(\mathrm{NCN})$ in Poland by Opus 11 research project 2016/21/B/ST10/03042.

\section{References}

Acreman M, Dunbar MJ. 2004. Defining environmental river flow requirements - a review. Hydrol Earth Syst Sci 8: 861-876.

Anibas C, Buis K, Verhoeven R, Meire P, Batelaan O. 2011. A simple thermal mapping method for seasonal spatial patterns of groundwater-surface water interaction. J Hydrol 397: 93-104.

Anibas C, Verbeiren B, Buis K, et al. 2012. A hierarchical approach on groundwater-surface water interaction in wetlands along the upper Biebrza River. Hydrol Earth Syst Sci 16: 2329-2346.

Armitage PD, Petts GE. 1992. Biotic score and prediction to assess the effects of water abstractions on river macroinvertebrates fo conservation purposes. Aquat Conserv: Mar Freshw Ecosyst 2: $1-17$.

Bączyk A, Wagner M, Okruszko T, Grygoruk M. 2018. Influence of technical maintenance measures on ecological status of agricultural lowland rivers - systematic review and implications for river management. Sci Total Environ 627: 189-199.

Bis B, Mikulec A. 2013. Przewodnik do oceny stanu ekologicznego rzek na podstawie makrobezkręgowców bentosowych. Warszawa: Biblioteka Monitoringu Srodowiska.

Bradley DC, Streetly M, Farren E, Cadman D, Banham A. 2014. Establishing hydroecological relationschips to manage the impacts of groundwater abstraction. Water Environ J 28: 114-123.

Campbell EY, Dunham JB, Reeves GH. 2020. Linkages between temperature, macroinvertebrates, and young-of-year Coho Salmon growth in surface-water and groundwater streams. Freshw Sci 39: $447-460$.

Chormański J, Berezowski T, Okruszko T, Ignar S. 2011. Hydrography and hydrology of the Upper Biebrza Basin. Contemporary Problems of Management and Environmental Protection, No. 7, "Issues of Landscape Conservation and Water Management in Rural Areas". URL: http://www.uwm.edu.pl/environ/vol07/vol07_ chapter14.pdf (accessed on 25.02.2021).

Clarke KR. 1993. Non-parametric multivariate analyses of changes in community structure. Aust J Ecol 18: 117-143.

Clarke KR, Gorley R. 2006. PRIMER v6: User Manual/Tutorial. Plymouth Marine Laboratory, UK.

Clarke KR, Warwick RM. 2001. Changes in Marine Communities: An Approach to Statistical Analysis and Interpretation. 2nd Edition, PRIMER-E. UK: Plymouth Marine Laboratory.

Conant Jr. B, Robinson CE, Hinton MJ, Russell HAJ. 2019. A framework for conceptualizing groundwater-surface water interactions and identifying potential impacts on water quality, water quantity, and ecosystems. J Hydrol 573: 609-627. 
Diaz M, Sinicyn G, Grodzka-Łukaszewska M. 2020. Modelling of Groundwater-Surface Water Interaction. Water 12 (3303): 1-19.

Fleckenstein JH, Krause S, Hannah DM, Boano F. 2010. Groundwater-surface water interactions: new methods and models to improve understanding of processes and dynamics. Adv Water Resour 33: 1291-1295.

Graeber D, Pusch MT, Lorenz S, Brauns M. 2013. Cascading effects of flow reduction on the benthic invertebrate community in a lowland river. Hydrobiologia 717: 147-159.

Grodzka-Łukaszewska M, PawlakZ, Sinicyn G. 2021. Spatial distribution of the water exchange through river cross-section - measurements and the numerical model. Arch Environ Protect 47: 69-79.

Grygoruk M, Frąk M, Chmielewski A. 2015. Agricultural rivers at risk: dredging results in a loss of macroinvertebrates. Preliminary observations from the Narew catchment, Poland. Water 7: 4511-4522.

Grygoruk M, Rannow S. 2017. Mind the Gap! Lessons from sciencebased stakeholder dialogue in climate-adapted management of wetlands. J Environ Manag 186: 108-119.

Jekatierynczuk-Rudczyk E. 2007. Strefa hyporeiczna, jej funkcjonowanie i znaczenie. Kosmos 56: 181-196.

Kalbus E, Reinstorf F, Schirmer M. 2006. Measuring methods for groundwater - surface water interactions: a review. Hydrol Earth Syst Sci 10: 873-887.

Klimaszyk P, Trawiński A. 2007. Ocena stanu rzek na podstawie makrobezkręgowców bentosowych. Indeks BMWP-PL. Poznań. URL: www.staff.amu.edu.pl/ zow/pobieranie/BMWP-PL.pdf.

Kołodziejczyk A, Koperski P. 2000. Bezkręgowce słodkowodne Polski. Wyd. Uniwersytetu Warszawskiego, Warszawa, 250 pp.

Kubosova K, Brabec K, Jarkovsky J, Syrovatka V. 2010. Selection of indicative taxa for river habitats: a case study on benthic macroinvertebrates using indicator species analysis and the random forest methods. Hydrobiologia 651: 101-114.

Lewandowski J, Meinikmann K, Krause S. 2020. Groundwatersurface water interactions: recent advances and interdisciplinary challenges. Water 12988.

Lewin I, Jusik S, Szoszkiewicz K, Czerniawska-Kusza I, Ławniczak AE. 2014. Application of the new multimetric MMI_PL index for biological water quality assessment in reference and human-impacted streams (Poland, the Slovak Republic). Limnologica 49: 42-51.

Ling Q, Song J, Gualtieri C, et al. 2020. Effect of Hyporheic Exchange on Macroinvertebrate Community in the Weihe River Basin, China. Water 12: 457.
Magliozzi C, Usseglio-Polatera P, Meyer A, Grabowski RC. 2019. Functional traits of hyporheic and benthic invertebrates reveal importance of wood-driven geomorphological processes in rivers. Funct Ecol 33: 1758-1770.

Marciniak M, Chudziak Ł. 2015. Nowa metoda pomiaru współczynnika filtracji osadów dennych. Przeglad Geologiczny 63: 919-925.

Mathers KL, Hill MJ, Wood PJ. 2016. Benthic and hyporheic macroinvertebrates distribution within the heads and tails of riffles during baseflow conditions. Hydrobiologia 794: 17-30.

Monk WA, Wood PJ, Hannah DM, Wilson DA, Extence CA, Chadd R. 2006. Flow variability and macroinvertebrate community response within riverine systems in England and Wales. River Res Appl 19: 595-615.

Obolewski K, Glińska-Lewczuk K, Jarząb N, et al. 2014. Benthic invertebrates in floodplain lakes of a polish river: structure and biodiversity analyses in relation to hydrological conditions. Pol J Environ Stud 23: 1679-1689.

Packman AI, Bencala KE. 2003. Relative roles of stream flow and sedimentary conditions in controlling hyporheic exchange. Hydrobiologia 494: 291-297.

Pepin DM, Hauer FR. 2002. Benthic response to groundwater-surface water exchange in 2 alluvial rivers in north-western Montana. $J$ North Am Bentholog Soc 21: 370-383.

Principe RE, Márquez JA, Cibils L. 2019. Distribution and habitat preference of Ephemeroptera and Trichoptera in subtropical mountain streams: implications for monitoring and conservation. Anais da Academia Brasileira de Ciências 91: e20180692.

Sanders LL. 1998. A Manual of Field Hydrogeology. New Jersey: Prentice Hall.

Vimos-Lojano D, Hampel H, Vázquez RF, Martínez-Capel F. 2020. Community structure and functional feeding groups of macroinvertebrates in pristine Andean streams under different vegetation cover. Ecohydrol Hydrobiol 20: 357-368.

Wood PJ, Armitage PD. 2004. The response of the macroinvertebrate community to low-flow variability and supraseasonal drought within a groundwater dominated stream. Arch Hydrobiol 161: 1-20.

Źurek S. 2005. Rzeźba i budowa geologiczna doliny Biebrzy, in Przyroda Biebrzańskiego Parku Narodowego, edited by A. Dyrcz, C. Werpachowski. Biebrzański Park Narodowy, Osowiec-Twierdza: $19-32$.

Cite this article as: Grygoruk M, Szałkiewicz E, Grodzka-Łukaszewska M, Mirosław-Świątek D, Oglęcki P, Pusłowska-Tyszewska D, Sinicyn G, Okruszko T. 2021. Revealing the influence of hyporheic water exchange on the composition and abundance of bottom-dwelling macroinvertebrates in a temperate lowland river. Knowl. Manag. Aquat. Ecosyst., 422, 37. 